\title{
A Comparison between Hybrid Therapy and Standard Triple Therapy for Helicobacter pylori Eradication in Patients with Uremia: A Randomized Clinical Trial
}

\author{
Atieh Makhlough ${ }^{1}$, Hafez Fakheri ${ }^{2 *}$, Samaneh Hojati ${ }^{3}$, Vahid Hosseini ${ }^{4}$, Zohreh Bari ${ }^{5}$
}

1. Associate Professor, Department of Nephrology, Gut and Liver Research Center, Mazandaran University of Medical Sciences, Sari, Iran.

2. Professor, Department of Gastroenterology, Gut and Liver Research Center, Mazandaran University of Medical Sciences, Sari, Iran.

3. Resident of Internal Medicine, Mazandaran University of Medical Sciences, Sari, Iran.

4. Associate Professor, Department of Gastroenterology, Gut and Liver Research Center, Mazandaran University of Medical Sciences, Sari, Iran.

5. Fellow of Gastroenterology, Mazandaran University of Medical Sciences, Sari, Iran.

\footnotetext{
* Corresponding Author:

Hafez Fakheri, MD

Professor, Department of Gastroenterology, Gut and Liver Research Center, Mazandaran University of Medical Sciences, Sari, Iran

Tel: + 981150670

Fax: +98 1150671

Email: hafezfakheri@gmail.com

Received: 25 Jul. 2015

Accepted: 21 Oct. 2015
}

\section{ABSTRACT}

\section{BACKGROUND}

The prevalence of peptic ulcer disease in hemodialysis patients is more than the general population. They are also more prone to complications including upper gastrointestinal bleeding. The aim of this study was to compare the efficacy of 14 days hybrid regimen with 14 days triple therapy for Helicobacter pylori (H. pylori) eradication in hemodialysis patients.

\section{METHODS}

Forty hemodialysis patients with naïve H.pylori infection were randomized to receive either hybrid regimen (pantoprazole $40 \mathrm{mg}+$ amoxicillin $500 \mathrm{mg}$, both twice a day during the first 7 days, followed by pantoprazole $40 \mathrm{mg}+$ amoxicillin $500 \mathrm{mg}+$ clarithromycin $500 \mathrm{mg}+$ tinidazole $500 \mathrm{mg}$, all twice a day, for the second 7 days, or standard triple therapy including pantoprazole $40 \mathrm{mg}$, clarithromycin $500 \mathrm{mg}$, and amoxicillin $500 \mathrm{mg}$, all twice a day for 14 days. H.pylori eradication was assessed by fecal H.pylori antigen test 8 weeks after the treatment.

\section{RESULTS}

All the patients completed the study. According to both intention to treat and per-protocol analyses, H.pylori eradication rates were 100\% (95\% confidence interval (CI): 100) in those who received hybrid therapy and 70\% (95\% CI: 69.4 $-70.8)$ in those who were treated by standard triple therapy $(p=0.02)$. Severe adverse effects were not reported by any patient; however, mild adverse effects were more frequent in those who received standard triple therapy $(p<0.05)$.

\section{CONCLUSION}

Hybrid regimen could achieve ideal H.pylori eradication rates with low rates of adverse effects.

\section{KEYWORDS}

Hybrid; Hemodialysis; Helicobacter pylori

Please cite this paper as:
GMakhlough A, Fakheri H, Hojati S, Hosseini V, Bari Z. A Comparison between Hybrid Ther-
apy and Standard Triple Therapy for Helicobacter pylori Eradication in Patients with Uremia: A
Randomized Clinical Trial. Disease Middle East J Dig Dis 2015;8:39-43. DOI :10.15171/
mejdd.2016.05
mejdd.2016.05

\section{INTRODUCTION}

Helicobacter pylori (H.pylori) is the most common infection worldwide. Almost half of the world's population is infected by the organism. ${ }^{1}$ It is associated with peptic ulcer disease (PUD), gastric/duodenal erosions, gastric adenocarcinoma, and gastric lymphoma both in healthy population and patients with uremia..$^{2-4}$ 
Studies have shown that PUD is more prevalent in H.pylori positive hemodialysis patients than the general population. ${ }^{5}$ Furthermore, these patients are more prone to gastrointestinal bleeding, partially because of the fragility of gastric mucosa and inevitable use of anticoagulant therapy during hemodialysis. ${ }^{6}$ Therefore, H.pylori treatment is an important issue in this group of patients.

On the other hand, patients with uremia, especially those with end-stage renal disease (ESRD) have some degrees of immune system dysfunction. Therefore, they have higher rates of infection and antibiotic use. This leads to higher rates of antibiotic resistance in this group of patients. ${ }^{7}$ Consequently, the eradication of H.pylori may be more difficult in such patients, because antibiotic resistance is the most common cause of failure to eradicate H.pylori. ${ }^{8}$

Hybrid regimen is a novel treatment including a proton pump inhibitor (PPI) + amoxicillin during the first 7 days, followed by quadruple regimen of a PPI + amoxicillin + clarithromycin + metronidazole/tinidazole for the second 7 days. The eradication rates achieved by hybrid regimen have been promising in most studies. Also, a recent review article considering H.pylori eradication regimens in west Asia has reported hybrid regimen as an ideal regimen for first line H.pylori therapy in this geographic region. ${ }^{9}$ However, to the best of our knowledge, no study has assessed the effects of hybrid regimen for H.pylori eradication in patients with uremia. Therefore, we designed a study to compare the effects of hybrid therapy with standard triple therapy in hemodialysis patients.

\section{MATERIALS AND METHODS}

From December 2013 to January 2014, forty hemodialysis patients with naïve H.pylori infection entered the study. H.pylori infection had been confirmed by both rapid urease test (RUT, Shim anzy, Tehran, Iran) and fecal H.pylori antigen test (Dahelwit 93, Germany). The reasons for gastrointestinal evaluation were long-standing dyspepsia, iron deficiency anemia, or being candidate for renal transplantation. Before starting the protocol, written informed con- sents were obtained from all the patients.

The exclusion criteria were age less than 18 years or above 85 years, any chronic disease that would hinder follow-up (such as liver failure, heart failure, chronic pulmonary disease, or history of malignancy), history of allergic reactions to any of the medications used in this study, history of gastric or esophageal surgery, using antibiotics during the previous week, pregnancy, or breastfeeding.

The patients were randomized into two groups, using computer-generated randomization. Twenty patients received hybrid regimen including: pantoprazole $40 \mathrm{mg}+$ amoxicillin $500 \mathrm{mg}$ both twice a day during the first 7 days, followed by pantoprazole $40 \mathrm{mg}+$ amoxicillin $500 \mathrm{mg}+$ clarithromycin $500 \mathrm{mg}+$ tinidazole $500 \mathrm{mg}$, all twice a day, for the second 7 days. The remaining 20 patients received standard triple therapy including: pantoprazole 40 $\mathrm{mg}$, clarithromycin $500 \mathrm{mg}$, and amoxicillin 500 $\mathrm{mg}$, all twice a day for 14 days.

The patients were advised to call the doctor in case of any severe side effects. After treatment, all patients were visited and were asked about the number of remained medications (if any). Compliance to treatment was considered excellent if the patient took more than $90 \%$ of the medications, good in case of taking $70-90 \%$ of the drugs and poor, if the patient used less than $70 \%$ of the prescribed medications.

H.pylori eradication was assessed by fecal H.pylori antigen test (Dahelwit 93, Germany) 8 weeks after the treatment. In order to calculate intention to treat eradication rates, all the patients who entered the study were included in the analysis. But in order to calculate per-protocol eradication rates, only data of those who completed the entire protocol with more than $90 \%$ compliance to treatment were analyzed.

Data were analyzed using IBM SPSS software for windows (version 16). Chi-square and tests were used as appropriate. $p$ values less than 0.05 were considered as statistically significant.

\section{RESULTS}

All the patients completed the study. Nineteen patients were men $(47.5 \%)$ and $21(52.5 \%)$ were 
women. The mean age was $51.3 \pm 16.9$ years. Demographic data including age, sex, history of gastrointestinal bleeding, endoscopic findings, the reasons for gastrointestinal evaluation, and the need for H.pylori eradication did not show statistically significant difference between the two groups (table 1). The indications for H.pylori eradication were: being candidate for renal transplantation, dyspepsia, or gastroduodenal ulcer or erosions. ${ }^{10}$

Six patients in the triple therapy group (30\%) reported mild adverse effects (four cases of metallic taste and two cases of malaise). Also, two patients who received hybrid regimen (10\%) complained of mild metallic taste $(p<0.05)$. However, compliance to treatment was excellent in all patients and no one interrupted treatment because of adverse effects of the treatment.

According to both intention to treat and per-protocol analyses, H.pylori eradication rates were 100\% (95\% CI: 100) in those who received hybrid regimen and 70\% (95\% CI: 69.41-70.89) in those who were treated by standard triple therapy ( $p=0.02$, figure 1$)$

\section{DISCUSSION}

Our study showed that hybrid regimen could eradicate H.pylori in $100 \%$ of patients, but the eradication rate achieved by standard triple therapy was disappointing. Furthermore, the rates of sideeffects of treatment were significantly lower in those who received hybrid regimen. However, both regimens were well tolerated and no one interrupted the treatment because of the adverse effects of the prescribed drugs.

If we consider H.pylori as an infectious disease, the ideal regimen would be the one that can eradicate H.pylori in more than $95 \%$ of the cases. ${ }^{11}$ Most of previous studies could not achieve optimal eradication rates in hemodialysis patients.

Comparing the results of our study with previous reports, standard triple therapy could not achieve ideal eradication rate. This is in concordance with most previous studies. According to a recent study performed by Makhlough and colleagues, 49 hemodialysis patients were randomized to receive either 14-day clarithromycin-containing triple therapy

\begin{tabular}{|c|c|c|c|}
\hline Variable & & Hybrid therapy & Triple therapy \\
\hline Male/ Female & & $11 / 9$ & $8 / 12$ \\
\hline Age (years) & & $51.0 \pm 19$ & $51.5 \pm 15$ \\
\hline History of GIB & & 1 & 4 \\
\hline \multirow{5}{*}{$\begin{array}{l}\text { Endoscopic } \\
\text { findings }\end{array}$} & $\begin{array}{l}\text { Gastric } \\
\text { ulcer }\end{array}$ & 4 & 10 \\
\hline & $\begin{array}{l}\text { Duodenal } \\
\text { ulcer }\end{array}$ & 1 & 3 \\
\hline & $\begin{array}{l}\text { Gastric } \\
\text { erosion }\end{array}$ & 12 & 4 \\
\hline & $\begin{array}{l}\text { Duodenal } \\
\text { erosion }\end{array}$ & 2 & 2 \\
\hline & $\begin{array}{l}\text { Erosive } \\
\text { gastro- } \\
\text { duode- } \\
\text { nopathy }\end{array}$ & 1 & 1 \\
\hline \multirow{3}{*}{$\begin{array}{l}\text { Indication for } \\
\text { gastrointestinal } \\
\text { evaluation }\end{array}$} & $\begin{array}{l}\text { Dyspepsia } \\
\text { symptoms }\end{array}$ & 4 & 5 \\
\hline & $\begin{array}{l}\text { Iron } \\
\text { deficiency } \\
\text { anemia }\end{array}$ & 5 & 6 \\
\hline & $\begin{array}{l}\text { Candidate } \\
\text { for renal } \\
\text { transplan- } \\
\text { tation }\end{array}$ & 11 & 9 \\
\hline
\end{tabular}

GIB: gastrointestinal bleeding

or sequential regimen. H.pylori eradication rates were $76.2 \%$ and $87.5 \%$ by per-protocol analysis, respectively. ${ }^{12}$ According to another study by Wang and co-workers on 40 hemodialysis patients, 7-day omeprazole-amoxicillin-clarithromycin(OAC) regimen could eradicate H.pylori in $86.8 \%$ of cases. ${ }^{13}$ In addition, Tsukada and colleagues reported $82.1 \%$ eradication rate using the same regimen for 39 hemodialysis patients. ${ }^{14}$ Sezer and others showed a high eradication rate $(94.1 \%)$ in 17 hemodialysis dependent patients using 14-day OAC regimen. ${ }^{15}$ However, Itatsu and colleagues reported low eradication rate $(72.7 \%)$ among 11 hemodialysis patients who had received 7-day lansoprazole-amoxicillinclarithromycin. ${ }^{16}$ On the other hand, Chang studied the effects of low-dose OAC on 33 hemodialysis patients and reported an eradication rate of $83.4 \%$ by per-protocol analysis. ${ }^{17}$

On the other hand, our study showed excellent (100\%) H.pylori eradication rate by hybrid regimen. Hybrid regimen is a novel H.pylori eradication protocol with promising eradication rates. 


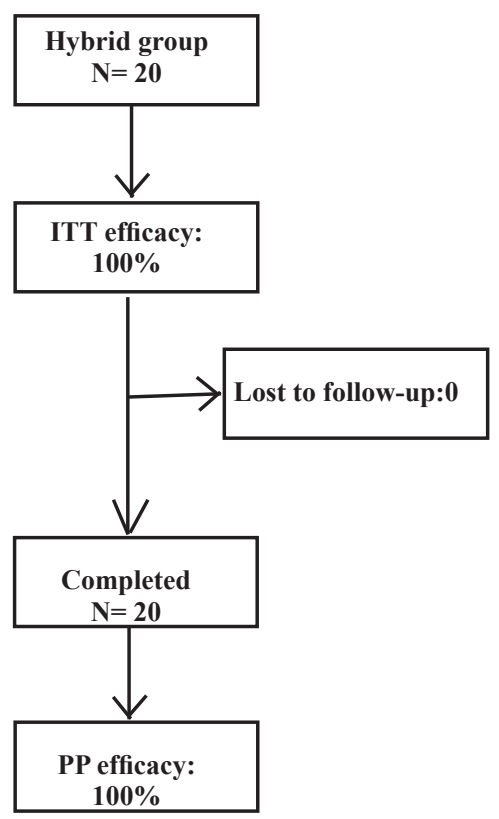

ITT: intention to treat;

PP: per-protocol

Fig. 1: Method of follow-up \& treatment efficacy

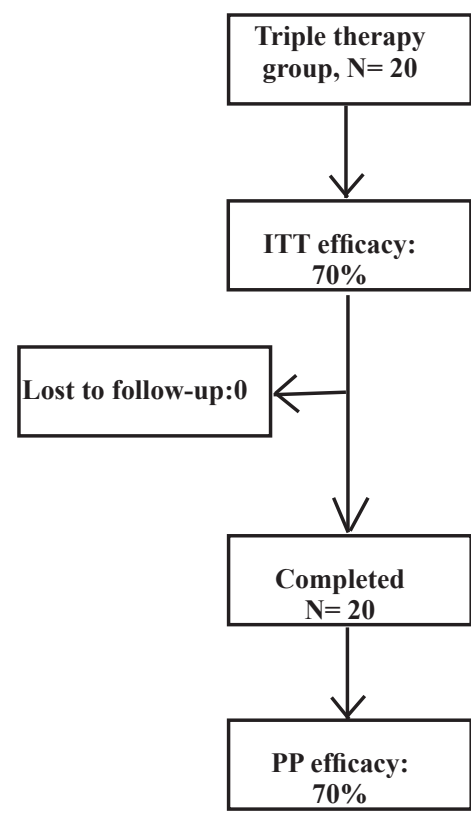

renal failure, either prior to renal transplantation or in patients on hemodialysis, is a predisposing factor for gastroduodenal mucosal lesions. ${ }^{6,22}$ These gastrointestinal complications can be directly associated with H.pylori infection. ${ }^{5}$ Also patients with uremia are more prone to complications of PUD than the general population. ${ }^{6}$ Furthermore, some studies have reported higher resistance rates to antibiotics in patients with uremia than the general population. ${ }^{23}$ Therefore, introducing an H.pylori eradication regimen with ideal eradication rates seems to be important in this group of patients and our study reported excellent H.pylori eradication rate by hybrid regimen.

Our study has some limitations. One of the main limitations was small number of patients that is because of evaluating a special group of patients (hemodialysis patients). Another important limitation was the unavailability of H.pylori culture. However, the strong point of the present study was to evaluate the effects of hybrid regimen in patients with uremia, because to the best of our knowledge, no study has been performed to evaluate the effects of hybrid therapy in hemodialysis patients

In conclusion, hybrid regimen could achieve ideal H.pylori eradication rate with low rate of side-effects and excellent compliance to treatment. Further 
studies with larger number of patients are suggested.

\section{ACKNOWLEDGEMENT}

This study was the graduation thesis of Dr. Samaneh Hojjati for her specialization degree in Internal Medicine.

\section{CONFLICT OF INTEREST}

The authors declare no conflict of interest related to this work.

\section{REFERENCES}

1. Egan BJ, Marzio L, O'Connor H, O'Morain C. Treatment of Helicobacter pylori infection. Helicobacter 2008;13 Suppl 1:35-40. DOI:10.1111/j.1523-5378.2008.00639.x.

2. Sugimoto M, Sakai K, Kita M, Imanishi J, Yamaoka Y. Prevalence of Helicobacter pylori infection in long-term hemodialysis patients. Kidney Int 2009;75:96-103. DOI:10.1038/ki.2008.508.

3. Gioe FP, Cudia B, Romano G, et al. Role and clinical importance of Helicobacter pylori infection in hemodialysis patients. G Chir 2008;29:81-4.

4. Suzuki H, Saito Y, Hibi T. Helicobacter pylori and Gastric Mucosa-associated Lymphoid Tissue (MALT) Lymphoma: Updated Review of Clinical Outcomes and the Molecular Pathogenesis. Gut liver 2009;3:81-7. DOI:http://dx.doi. org/10.5009/gnl.2009.3.2.81

5. Khedmat H, Ahmadzad-Asl M, Amini M, Lessan-Pezeshki M, Einollahi B, Pourfarziani V, et al. Gastro-duodenal lesions and Helicobacter pylori infection in uremic patients and renal transplant recipients. Transplant Proc 2007;39:1003-7. DOI:http://dx.doi.org/10.1016/j.transproceed.2007.03.034.

6. Fabian G, Szigeti N, Kovacs T, Nagy J. An unusual multiplex cause of severe gastrointestinal bleeding in a haemodialysed patient. Nephrol Dial Transplant 2000;15:186971. DOI:10.1093/ndt/15.11.1869.

7. Aydemir S, Boyacioglu S, Gur G, Demirbilek M, Can FK, Korkmaz M, et al. Helicobacter pylori infection in hemodialysis patients: susceptibility to amoxicillin and clarithromycin. World J Gastroenterol 2005;11:842-5. DOI:10.3748/wjg.v11.i6.842.

8. Graham DY, Fischbach L. Helicobacter pylori treatment in the era of increasing antibiotic resistance. Gut 2010;59:1143-53. DOI:10.1136/gut.2009.192757.

9. Fakheri H, Bari Z, Aarabi M, Malekzadeh R. Helicobacter pylori eradication in West Asia: a review. World J Gastroenterol 2014;20:10355-67. DOI:10.3748/wjg.v20.i30.10355.

10. Knoll G, Cockfield S, Blydt-Hansen T, Baran D, Kiberd B, Landsberg D, et al. Canadian Society of Transplantation: consensus guidelines on eligibility for kidney transplantation. CMAJ 2005;173:1181-4. DOI:10.1503/cmaj.051291.

11. Graham DY, Lu H, Yamaoka Y. A report card to grade Helicobacter pylori therapy. Helicobacter 2007;12:275-8. DOI:10.1111/j.1523-5378.2007.00518.x.
12. Makhlough A, Fakheri H, Farkhani AR, Seddighi O, Hossieni $\mathrm{SV}$, Khademloo M, et al. A comparison between standard triple therapy and sequential therapy on eradication of Helicobacter pylori in uremic patients: A randomized clinical trial. $A d v$ Biomed Res 2014;3:248. DOI:10.4103/2277-9175.146372

13. Wang YL, Sheu BS, Huang JJ, Yang HB. Noninvasive stool antigen assay can effectively screen Helicobacter pylori Infection and assess success of eradication therapy in hemodialysis patients. Am J Kidney Dis 2001;38:98-103. DOI:http://dx.doi.org/10.1053/ajkd.2001.25200.

14. Tsukada K, Miyazaki T, Katoh H, Masuda N, Ojima H, Fukai Y, et al. Seven-day triple therapy with omeprazole, amoxycillin and clarithromycin for Helicobacter pylori infection in haemodialysis patients. Scand J Gastroenterol 2002;37:1265-8. DOI:10.1080/003655202761020524.

15. Sezer S, Ibis A, Ozdemir BH, Ozdemir FN, Külah E, Boyacioğlu S, et al. Association of helicobacter pylori infection with nutritional status in hemodialysis patients. Transplant Proc 2004;36:47-9. DOI:http://dx.doi. org/10.1016/j.transproceed.2003.11.023.

16. Itatsu T, Miwa H, Nagahara A, Kubota M, Miyazaki A, Sato N, et al. Eradication of Helicobacter pylori in hemodialysis patients. Ren Fail 2007;29:97-102. DOI:10.1080/08860220601039122.

17. Chang WC, Jo YI, Park HS, Jegal J, Park JH, Lee JH, et al. Helicobacter pylori eradication with a 7-day low-dose triple therapy in hemodialysis patients. Clin Exp Nephrol 2010;14:469-73. DOI:10.1007/s10157-010-0319-7.

18. De Francesco V, Hassan C, Ridola L, Giorgio F, Ierardi E, Zullo A. Sequential, concomitant and hybrid first-line therapies for Helicobacter pylori eradication: a prospective randomized study. J Med Microbiol 2014;63:748-52. DOI:10.1099/jmm.0.072322-0.

19. Oh DH, Lee DH, Kang KK, Park YS, Shin CM, Kim N, et al. Efficacy of hybrid therapy as first-line regimen for Helicobacter pylori infection compared with sequential therapy. $J$ Gastroenterol Hepatol 2014;29:1171-6. DOI:10.1111/jgh.12518.

20. Zullo A, Scaccianoce G, De Francesco V, Ruggiero V, D'Ambrosio P, Castorani L, et al. Concomitant, sequential, and hybrid therapy for $\mathrm{H}$. pylori eradication: a pilot study. Clin Res Hepatol Gastroenterol 2013;37:647-50. DOI:10.1016/j.clinre.2013.04.003.

21. Sardarian H, Fakheri H, Hosseini V, Taghvaei T, Maleki I, Mokhtare M. Comparison of hybrid and sequential therapies for Helicobacter pylori eradication in Iran: a prospective randomized trial. Helicobacter 2013;18:129-34. DOI:10.1111/hel.12017.

22. Cocchiara G, Romano M, Buscemi G, Maione C, Maniaci S, Romano G. Advantage of eradication therapy for Helicobacter pylori before kidney transplantation in uremic patients. Transplant Proc 2007;39:3041-3. DOI:http://dx.doi. org/10.1016/j.transproceed.2007.07.095.

23. Jaffer Y, Selby NM, Taal MW, Fluck RJ, McIntyre CW. A meta-analysis of hemodialysis catheter locking solutions in the prevention of catheter-related infection. Am J Kidney Dis 2008;51:233-41. DOI:10.1053/j.ajkd.2007.10.038. 